\title{
Abnormal Excretion of Corticosteroid Sulphates in Patients with Breast Cancer
}

\author{
P. C. GHOSH, E. LOCKWOOD, G. W. PENNINGTON
}

British Medical fournal, 1973, 1, 328-330

\section{Summary}

In a prehiminary study, the 24-hour urinary excretion of corticosteroid sulphates and free cortisol have been measured in a group of patients with breast cancer and compared with the excretion of the same compounds in a group of normal women of similar age. Excretion of corticosteroid sulphates in the breast cancer group was found to be markedly raised. In a small number of patients with localized cancer of sites other than the breast the level of corticosteroid sulphate was not raised. If proved metastases were present a noticeable rise was observed.

\section{Introduction}

The importance of the excretion of neutral 17-oxosteroids in breast cancer in the prediction of the responsiveness to endocrine gland ablation was first studied by Allen et al. (1957). Since then a number of other workers have substantiated their findings (Bulbrook et al., 1960; Bulbrook et al., 1962a, 1962b; Kumaoka et al., 1968).

Bulbrook et al. (1964) described a derived formula, which they termed the "discriminant function," which expressed the values of 11-deoxy-17-oxosteroid excretion in relation to that of the 17-oxogenic steroids. Their work suggests that patients with a positive discriminant generally respond better to endocrine organ ablation than patients with a negative result. Some doubts have recently been expressed about the usefulness of the "discriminant function" in early breast cancer (Wade et al., 1969) or where there is abnormal thyroid function (Sneddon et al., 1968).

Plasma studies have shown that patients with advanced breast cancer have levels of 17-oxogenic steroids which are greatly above the normal range, although such raised levels are virtually absent in patients with early disease (Deshpande et al., 1965). Although urinary 17-oxosteroid and oxogenic steroid excretion has gained importance in the prognosis of the disease, no attempt appears to have been made to investigate the excretion of urinary corticosteroid sulphates and free cortisol despite the fact that the ability of breast cancer tissue to produce sulphated compounds has been well shown (Dao, 1969).

In this preliminary study the excretion of corticosteroid sulphates and free cortisol has been studied in both normal women and women at the time of the diagnosis of breast cancer, of similar age groups. It is hoped that this may prove a useful parameter with respect to prognosis.

Sheffield and Region Endocrine Investigation Centre, Jessop Hospital for Women, Sheffield $S 37 R E$

P. C. GHOSH, M.sc., PH.D., Research Associate, Medical Research Council E. LOCKWOOD, B.sc., PH.D., Research Associate, Medical Research Council

G. W. PENNINGTON, M.D., M.R.C.PATH., Consultant Chemical Pathologist
Patients, Material, and Methods

Full 24-hour urinary samples were collected from patients with breast cancer subsequently confirmed by histological examination. Control samples were collected from healthy hospital employees, none of whom had evidence of any endocrine abnormality. Altogether, 29 patients with breast cancer of various stages (aged 39-65 years: mean 49.25 \pm 7.03 ) and 20 normal female controls (aged 40-62 years: mean $51.35 \pm 5.68)$ were investigated. In all samples the output of corticosteroid sulphate and cortisol was estimated. In order to determine if differences in excretion were present when the cancer site was other than in the breast a group of patients with cancer of other sites were also studied.

The free cortisol was determined by competitive protein binding radioassay (Hsu and Bledsoe, 1970). The corticosteroid sulphates were quantitated as a group. No attempt was made to separate the individual components-namely, cortisol, cortisone, corticosterone, and 11-dehyrocorticosterone sulphates.

It has been conclusively shown that only these corticosteroids are capable of binding with the corticosteroid binding globulin obtained from late pregnancy plasma (Kolanowski and Pizarro, 1969; Ghosh et al., 1971), the assay being carried out on an aliquot $(0.2 \mathrm{ml})$ of a 24 -hour specimen of urine. The sample was washed with $2 \times 2.5$ volumes of ethyl acetate to remove the free steroids. The steroidal sulphate conjugates were then extracted on two occasions with 10 volumes and 2.5 volumes of ethanol: acetone $(2: 1)$. The pooled extracts were evaporated in a centrifuge tube under nitrogen and selectively solvolysed for 18 hours at $37^{\circ} \mathrm{C}$. The reagent mixture was then neutralized with pyridine and evaporated under a stream of nitrogen. The liberated steroids were dissolved in $0.2 \mathrm{ml}$ of water and washed with 10 volumes of light petroleum. The corticosteroids were extracted with 10 volumes of dichloromethane, quantitation being carried out by the protein binding technique described for cortisol (Hsu and Bledsoe, 1970). The values were expressed as $\mu \mathrm{g}$ of free steroid in 24 hours. This method of estimation, together with an assessment of its precision, accuracy, and specificity has been published elsewhere (Ghosh et al., 1972).

\section{Results}

The daily output of corticosteroid sulphates and free cortisol in patients with breast cancer and in normal controls of a similar age is shown in fig. 1. The range, mean, and standard error of mean are shown in table I. The regression lines have been drawn from the relative values obtained for the corti-

TABLE I-Urinary Excretion ( $\mu g / 24 \mathrm{hr}$ ) of Corticosteroid Sulphates and Cortisol in Patients with Breast Cancer and in Normal Controls. The Values are range, mean, ( \pm standard error of mean)

\begin{tabular}{|c|c|c|c|c|c|c|c|}
\hline \multicolumn{5}{|c|}{ Group } & \multirow{2}{*}{$\begin{array}{l}\text { No. } \\
29\end{array}$} & \multirow{2}{*}{$\begin{array}{c}\begin{array}{c}\text { Corticosteroid } \\
\text { Sulphates }\end{array} \\
20 \cdot 2-284 \cdot 8 \\
106 \cdot 6( \pm 15 \cdot 2)\end{array}$} & \multirow{2}{*}{$\begin{array}{c}\text { Cortisol } \\
26 \cdot 3-189 \cdot 7 \\
90 \cdot 8( \pm 6 \cdot 4)\end{array}$} \\
\hline Cancer & .. & .. & . & . & & & \\
\hline Normal & .. & .. & .. & .. & 20 & $\begin{array}{l}0.0-84.9 \\
41.5( \pm 5.6)\end{array}$ & $\begin{array}{l}0 \cdot 0-195 \cdot 8 \\
61 \cdot 6( \pm 12 \cdot 6)\end{array}$ \\
\hline
\end{tabular}




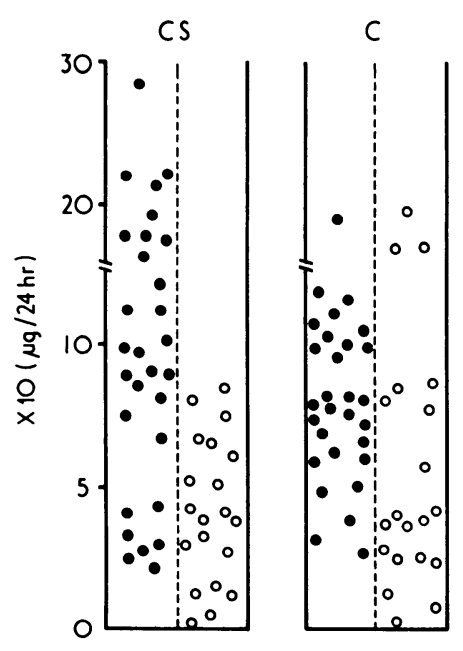
FIG. 1-Corticosteroid sulphate (CS) and free cortisol (C) excretion in breast
cancer ( $O$ ) and in normal controls (O). Results are expressed as $\mathrm{\mu g}$ of unconjugated steroids in 24 hours.

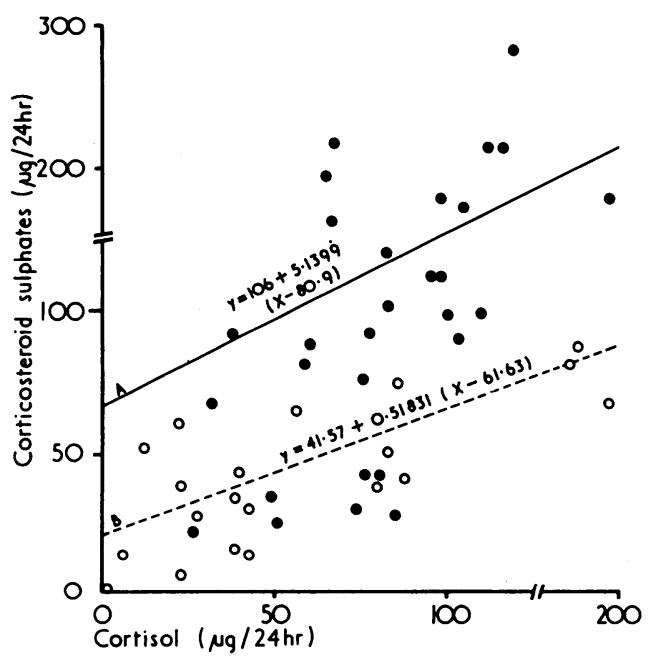

FIG. 2-Relative excretion of corticosteroid sulphate and cortisol in 24 hours. The regression curve $A$ in patients with breast cancer (O) and curve $B$ in normal controls (O).

costeroid sulphates and cortisol, from which the difference between the two experimental groups can easily be ascertained (fig. 2).

The clinical history and the output of corticosteroid sulphates and cortisol in patients who have been diagnosed to be suffering from cancer in sites other than the breast are summarized in table II.

Statistical analysis using the Student $t$ test shows that there is a highly statistical difference between normal controls and breast cancer-t $=4.71(0.05>P>0.02)$-with respect to the excretion of corticosteroid sulphates, although the

TABLB II-Urinary Excretion ( $\mu g / 24 \mathrm{hr}$ ) of Corticosteroid Sulphates and Cortisol in Patients with Cancer at Different Sites other than in the Breast

\begin{tabular}{|c|c|c|c|c|}
\hline $\begin{array}{l}\text { Case } \\
\text { No. }\end{array}$ & Age & Clinical History & $\begin{array}{l}\text { Corti- } \\
\text { costeroid } \\
\text { Sulphates }\end{array}$ & Cortisol \\
\hline $\begin{array}{l}1 \\
1 \mathrm{a} \\
\mathbf{1 b}\end{array}$ & $\begin{array}{l}65 \\
65 \\
65\end{array}$ & $\begin{array}{l}\text { Cancer of uterus, widespread metastases } \\
\text { Six days after oophorectomy } \\
10 \text { days after oophorectomy and two }\end{array}$ & $\begin{array}{r}175 \cdot 05 \\
24 \cdot 40 \\
50 \cdot 50\end{array}$ & $\begin{array}{r}147 \cdot 00 \\
38 \cdot 50 \\
39 \cdot 20\end{array}$ \\
\hline $\begin{array}{l}2 \\
3 \\
4 \\
5 \\
6 \\
7 \\
7 \mathrm{a} \\
8\end{array}$ & $\begin{array}{r}41 \\
48 \\
58 \\
64 \\
62 \\
57 \\
57 \\
5\end{array}$ & $\begin{array}{l}\text { Cancer of urethra with metastases } \\
\text { Cancer of ovary } \\
\text { Cancer of cervix } \\
\text { Adenocarcinoma of uterus } \\
\text { Cancer of uterus } \\
\text { Cancer of abdomen. Metastases } \\
7 \text { days after hysterectomy } \\
\text { Neoplastic mass in abdomen (original } \\
\text { site unknown) }\end{array}$ & $\begin{array}{r}240.60 \\
154.53 \\
63.00 \\
71.25 \\
20.05 \\
111.56 \\
185.25 \\
55.00\end{array}$ & $\begin{array}{r}59.50 \\
51.70 \\
12.80 \\
106.25 \\
135.00 \\
197.62 \\
114.56 \\
69.00\end{array}$ \\
\hline
\end{tabular}

difference is only marginally significant with respect to cortisol- $t=1.73(0.20>\mathrm{P}>0.10)$.

\section{Discussion}

The aim of this study was to elucidate the possible relation between the excretion of corticosteroid sulphates and free cortisol and the occurence of carcinoma of the breast. Previous in-vitro work by Dao (1969) showed that some primary and metastatic cancer cells are able to form steroid sulphates.

The present results now indicate that there is a pronounced difference in corticosteroid sulphate output between normal women and women with carcinoma of the breast of similar age. It is not known if the tumour size or the presence or absence of local or distant spread affects the output or, indeed, if the excretion of such increased amounts are casually related to the tumour, although the work of Dao (1969) appears to indicate that this is a distinct possibility. Dao also suggested that the capacity to sulphoconjugate steroids by the tumour tissue may bear some relation to the response to adrenalectomy or other forms of endocrine organ ablation.

In one of the reported cases of carcinoma of the breast oophorectomy was carried out and resulted in a noticeable diminution of corticosteroid sulphate output $(218.7 \mu \mathrm{g} / 24 \mathrm{hr}$ to $88.9 \mu \mathrm{g} / 24 \mathrm{hr}-37$ days postoperatively). It is of interest to note that the cortisol level showed a modest rise $(67 \cdot 7 \mu / 24$ $\mathrm{hr}$ to $104.9 \mu \mathrm{g} / 24 \mathrm{hr}$ ). The variation in sulphate/cortisol ratios was pronounced, being 3.23 before and 0.85 after oophorectomy. This solitary finding is in agreement with recent studies which indicate that there are various types of breast tumour tissue which can be classified according to their requirements of oestrogen for survival (Salih et al., 1972).

The other group of patients with cancers other than in the breast (summarized in table II) also show significant variation in their output of corticosteroid sulphate. The patients with proved metastases appear to excrete large amounts of these conjugates whereas others with apparently localized lesions provide values within the normal range.

Case 1 showed a dramatic fall in corticosteroid sulphate excretion six days after bilateral oophorectomy for uterine cancer. This suggests that some cells of the primary tumour tissue or metastases possibly responsible for the synthesis of sulphate may also require oestrogens for their survival. A subsequent rise in output suggests the possible presence of non-oestrogen dependent cells, which are perhaps more directly dependent on adrenal corticosteroids than on ovarian hormones for their growth and survival. In spite of therapy in case 1 the patient died 12 weeks later because of widespread carcinomatosis.

At this stage of the investigation neither the severity of the lesion at the time of diagnosis of carcinoma of the breast nor the possible correlation between corticosteroid sulphate excretion and prognosis have been considered. It is also evident that tumours other than in the breast excrete these compounds, particularly when metastases have recurred.

Further work is currently in progress to extend these findings.

This work has been suported by the Medical Research Council of Great Britain. Thanks are due to Mrs. N. Baddley, for organizing the urinary specimens, and for her technical help.

\section{References}

Allen, B. J., Hayward, J. L., and Merrivale, W. H. H. (1957). Lancet, brook, R. D., Greenwood, F. C., and Hayward, J. L. (1960). Lancet, 1,1154 .

Bulbrook, R. D., Hayward, J. L., Spicer, C. C., and Thomas, B. S. (1962a). Lancet, 2, 1235 . J. L., Spicer, C. C., and Thomas, B. S. Bulbrook, R. D., Hayward, J. L., Spicer, C. C., and Thomas, B. S.
(1962b). Lancet, 2, 1238.
Bulbrook, R. D., Hayward, J. L., and Thomas, B. S. (1964). Lancet, 1, 945 . 
Dao, T. L. (1969). The Human Adrenal Gland and its Relation to Breast Cancer, ed. K. Griffiths and E. H. D. Cameron, p. 99. Cardiff, Alpha Omega Alpha. Deshpande, N., Hayward, J. L., and Bulbrook, R. D. (1965). fournal of Ghosh, P. C., Lockwood, E., and Pennington, G. W. (1971). Steroidologia, Ghosh, P. C., Lockwood, E., and Pennington, G. W. (1972). Steroids
and Lipids Research, 3, 75.
Hsu, T. H., and Bledsoe, T. (1970). fournal of Clinical Endocrinology and Metabolism, 30, 443.

Kolanowski, J., and Pizarro, M. A. (1969). Annales d'Endocrinologie, 30, 177. Kumaoka, S., Sakauchi, N., Abe, O., Kusama, M., and Takatani, O. (1968). Fournal of Clinical Endocrinology and Metabolism, 28, 667.

Salih, H., Flax, H., and Hobbs, J. R. (1972). Lancet, 1, 1198.

Sneddon, A., Steet, J. M., and Strong, J. A. (1968). Lancet, 2, 892

Wade, A. P., Davis, J. C., Tweedie, M. C. K., Clarke, C. A., and Haggart, B. (1969). Lancet, 1, 853.

\title{
Pleural Effusion with Pancreaticopleural Fistula
}

\author{
M. TOMBROFF, A. LOICQ, J.-P. DE KOSTER, L. ENGLEHOLM, J.-P. GOVAERTS
}

British Medical fournal, 1973, 1, 330-331

\section{Summary}

Three patients with pleural effusion were found to have pancreaticopleural fistulas passing through an opening in the diaphragm are reported. In one case the effusion was purulent and originated from an abscess of the pancreas. Retrograde pancreatography during operation defined the course of.the fistula. In two other cases the fistula was demonstrated by radiography after intrapleural injection of contrast medium. The diagnostic importance of injecting contrast medium early into the pleural cavity in cases of effusion rich in amylase, before lung expansion obscures the fistula, is emphasized. Cases of pancreaticopleural fistula may be commoner than supposed.

\section{Introduction}

Pleural effusions associated with pancreatitis are generally thought to result from the diffusion of pancreatic enzymes into the pleura through transdiaphragmatic ducts. More rarely, cases have been reported of fistulization of a pancreatic pseudocyst either into the mediastinum along the diaphragmatic pillars (Stoppa, et al., 1970) or into the pleura via the diaphragm (Poppel, 1959; Roseman et al., 1960; Bergmann et al., 1965; Malaisse et al., 1967; Dubois et al., 1969). We report here three recent cases of pleural effusion of pancreatic origin in which there was a transdiaphragmatic fistula.

\section{Case Reports}

CASE 1

A 67-year-old man was admitted to hospital complaining of epigastric pain and loss of weight. There was no history of slcoholism, but 10 years previously he had been investigated because of epigastric pain and was found to have diabetes. Apart from epigastric tenderness, nothing abnormal was found on admission. A few days later a large left pleural effusion developed, accompanied by pyrexia. Paracentesis produced $600 \mathrm{ml}$ of purulent fluid from which mainly Gram-negative organisms were cultured. The amylase content of the pleural fluid was 280 Somogyi U/100 ml, whereas the serum amylase was only 140 Somogyi U/100 ml. Radiography showed a filling defect on the internal edge of the second part

Brugmann Hospital, University of Brussels, Brussels M. TOMBROFF, M.D., Associate, Department of Medicine A. LOICQ, M.D., Associate, Department of Medicine

J.-P. DE KOSTER, M.D., Head, Department of Chest Diseases L. ENGELHOLM, M.D., Associate, Department of Radiology J.-P. GOVAERTS, M.D., Associate, Department of Surgery of the duodenum due to external compression. This abnormality was confirmed by hypotonic duodenography.

These findings suggested a diagnosis of pancreatic abscess complicated by purulent pleurisy and this was confirmed by laparotomy, which revealed an enlarged, nodular, and hardened pancreas. Retrograde pancreatography during operation showed a dilated sinus communicating with a suprapancreatic convoluted abscess cavity which extended into the thorax by a narrow fistula. A pancreaticojejunostomy by the method of Roux was performed, and the postoperative period was uneventful. The effusion did not recur. Two years later the patient had a calcareous pancreatitis.

\section{CASE 2}

A 32-year-old man was admitted to hospital complaining of sudden onset of left-sided chest pain. He had a history of alcoholism and of attacks for several months of severe epigastric pain radiating to the back but not related to meals. After one of these attacks he underwent appendicectomy and resection of a Meckel's diverticulum, but without improvement in his symptoms.

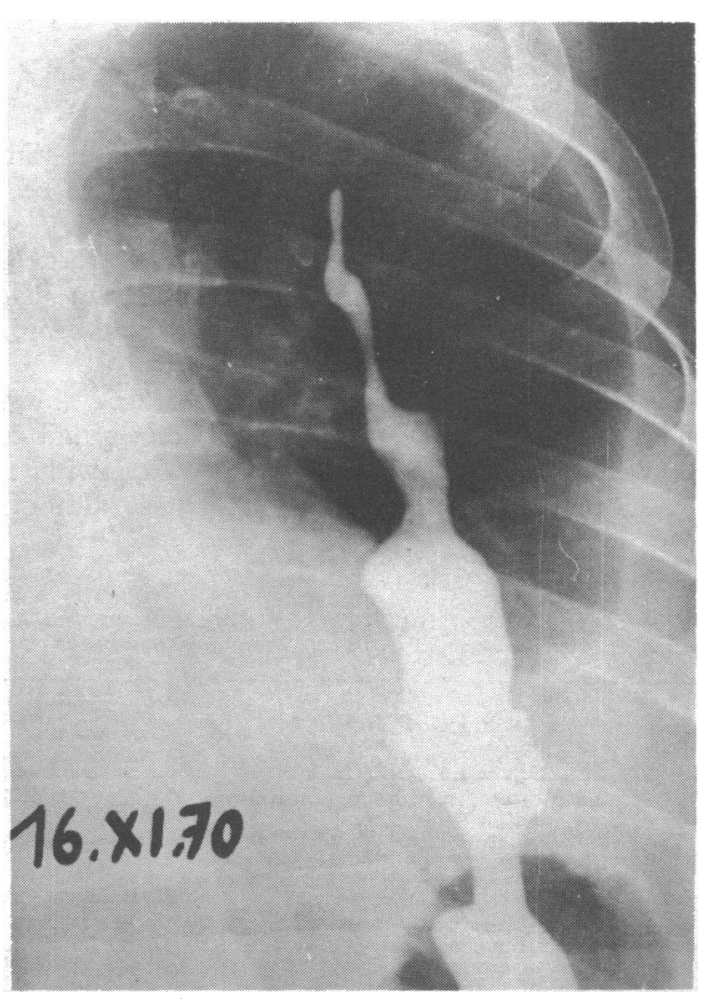

Anterior view. Patient is inclined almost $45^{\circ}$. The contrast medium is visible in the thoracic cavity, from which it extends through the diaphragm into the abdomen where it is superimposed on gastric shadow. 